\title{
UN TEMA A DEBAT: MODERNITAT I TRADICIO
}

Encetem aquesta nova època de "Papers» amb un recull de treballs i reflexions sobre un tema que considerem situat, athora, al centre de la problemàtica social i de l'anàlisi sociològica: el de la modernitat, de les seves formes, de la seva vigència $i$, per què no, de les seves consequùències, quan ja l'indiscutible domini d'aquest concepte, com a paradigma d'un conjunt de normes i pràctiques socials, comença a declinar i a esdevenir problemàtic.

Per tant, modernitat, en primer lloc, $\mathfrak{i}$ amb èmfasi especial. Més que tradició, ja més lluny de nosaltres. Però sense oblidar encara totalment els camins que han conduil de l'una a l'altra, i les transformacions que s'han produit en aquest traspàs.

En efecte, des del punt de vista de la sociologia, hi ha dos moments que podem considerar privilegiats per a l'anàlisi, perquè faciliten la comparació entre un abans i un després que ens vénen marcats per les diferències. El primer moment és el de la penetració de la modernitat en el món tradicional, aquell en què, no les idees, sinó les pautes de comportament pròpies de la modernitat corquen els fonaments de les institucions establertes, fins arribar a construir, en allò que aparentment és el trasbals d'un enderrocament, un paisatge nou.

L'emergència d'una societat diferent a la tradicional, «moderna», ba 
estat objecte d'un gran nombre de reflexions. Ha estat, fins i tot, un dels objectes més consistents de la sociologia. Ara bé, malgrat l'existència d'un bon nombre de treballs que el tracten, el tema del pas de la societat tradicional a la moderna no està esgotat.

I no està esgotat perquè avui no el contemplem ja des dels supòsits de la modernitat, és a dir, des d'un conjunt d'ideologies i pràctiques establertes amb una certa coherència, sinó que el podem plantejar des de la perspectiva que dóna l'esfondrament d'aquesta coherència. El plantegem des del segon moment privilegiat: el del traspàs del domini de la modernitat a una altra etapa, que provisionalment, i mancats de perfils suficients, anomenem postmoderna.

Bls ritmes desiguals del desenvolupament social condueixen a una situació en la que, encara no esvait del tot el món tradicional, comença ja, en alguns àmbits, a ser caduc allò que va substituir-lo. A Catalunya, per exemple, el procés de modernització ja està molt avançat; queden només alguns reductes on es mantenen pautes tradicionals, $i$ encara aquestes ja es troben molt amenaçades. Arribats a aquest punt, però, la modernitat ha desvetllat gtan part de les febleses que comportava, $i$ aquelles pautes tradicionals adquireixen nova força, no com a normes orientadores de les conductes teals, sinó corn a evocacions d'uns temps perfectes, impregnats d'un ordre collectiu que deslliurava de l'angoixa i donava sentit a l'existència. Encara els pagesos del Pallars o de la Terra Alta malden per modernitzar-se, $i$ ja les avantguardes ciutadanes enyoren, idealment, tot allò que tant els costa a aquells de desempallegat-se'n.

Aquesta superposició de temps històtics, de moments de canvi, permet una consideració, distinta $i$ distant alhora, del doble moviment de traspàs: redescobrim que les societats tradicionals havien resolt alguns dels problemes que la societat moderna va deixar pendents. Ens podem allunyar, sobretot, d'un judici de valor immediat, per endinsar-nos en l'anàłisi de dues arquitectures socials, cadascuna de les quals té els seus punts forts i febles, les seves falles $i$ les seves troballes. $I$, qüestió oberta, podem formular hipòtesis sobre el graus de similitud i de diferència que les caracteritza, podem relativitzar la noció mateixa de canvi, tot $i$ assenyalant-ne les seves dimensions.

Més enllà, però, d'aquest exercici comparatiu, cal, sobretot, analitzar la modernitat. La modernitat ja no és avui el lloc geomètric on sembien coincidir tots els esforços de resolució dels problemes socials. Ha passat I'hora en què la norma social salvadora era clara: calia modernitzar. Les transformacions fruit de la modernització han enderrocat institucions i pràctiques que eren alhora producte d'una dominació i d'una experiència vital collectiva. I aquest enderrocament ha generat noves contradiccions, 
poc visibles inicialment, però que ja se'ns presenten amb una força supefior a les que percebem en una societat tradicional ja liunyana. Contradiccions degudes, encara una vegada, a la implantació de noves formes de dominació, de noves necessitats, de noves ideologies. Contradiccions sovint viscudes d'una manera dramàtica, perquè tenen, con a primera caixa de ressonància, una consciència individual extremadament complexa, producte, ella mateixa, de la modernització. Contradiccions sorgides de desequilibris en les funcions socials bàsiques, com per exemple l'èmfasi en la racionalització, en la necessitat de triomf personal o en el predomini dels valors de transformació sobre els de permanència.

Ens cal, sobretot, fer el balanç de la modernitat, o, com diu Berger, la crítica de la modernitat, és a dir, restablir els seus valors i les seves mancances. Crítica que no es planteja des d'un altre paradigma de virtuts socials, que permeti aprovar o suspendre la modernitat, sinó més aviat fer el recompte d'allò que s'ha guanyat i d'allò que s'ha perdut, i aclarir què en queda La postmodernitat pot ésser terrible si només és, socialment, l'intent de retorn enrera, la retrobada d'un ordre que fóta només l'ordre de l'estancament, la repetició de cicles establerts, com sembla insinuar-se en alguns àmbits.

La postmodernitat, pensem, encara haurà d'intentar salvar molts dels valors de la modernitat, perquè l'immobilisme, per més coherent que sigui, ja no és suportable ni per als individus entrenats a l'angoixa de la tealització personal ni per a les collectivitats esperonades pel desig de possessió, com a dimensió fonamental del viure.

Heus aquí algunes de les raons que ens han conduit a tractar aquesta temàtica, que només queda encetada en els treballs que presentem. Iniciem aquest bloc temàtic amb un article de $\mathrm{P}$. Berger que és precisament una invitació a la crítica de la modernitat i que ens dóna, d'una manera admirable, al nostre parer, les claus d’algunes de les qüestions més rellevants que cal tenir presents. Incloem, en segon lloc, un capítol de la tesi de $\mathrm{S}$. Cardús, que ens dóna el nexe entre tradició i modernitat, és a dir, que se situa volgudament en el primer moment d'anàlisi que hem assenyalat. L'un i l'altre, des de nivells d'abstracció diferents, configuren els extrems de l'arc temporal pel qual ha transcorregut Ia modernitat.

Els segueixen dos textos en forma de conversa, caràcter que els permet una major flexibilitat temàtica. Pensada inicialment per a tractar l'evolució en el tractament social de l'espai, la taula rodona en què havien de participar X. Rubert de Ventós, J. Muntañola i A. Arió ha esdevingut finalment una doble entrevista, tan plena de suggetiments que hem decidit publicar-la integra. De la consideració de l'espai es passa a un recorregut per temes múltiples, sota el fil conductor de la crítica de la modernitat. Si el 
«Papers»: Revista de Sociologia

discurs és menys acabat que en els dos primers textos, té l'avantatge de produir-se com una autèntica bullida, sota la qual, cal advertir-ho, s'endevinen ja les línies mestres d'una lectura travada de la modernitat. 